\title{
COPULATORY PATTERN SUPPORTS GENERIC PLACEMENT OF SCHIZOCOSA AVIDA (WALCKENAER) (ARANEAE: LYCOSIDAE) ${ }^{1}$
}

\author{
By Jerome S. Rovner \\ Department of Zoology, Ohio University, Athens, Ohio 4570r
}

The wolf spider genus Schizocosa was established in 1904 by Chamberlin. He subsequently (I908) transferred several species (bilineata, crassipes, and saltatrix) from their former placement in the genus Lycosa to the genus Schizocosa. Such a transfer was also recommended for Lycosa avida Walckenaer by Gertsch and Wallace (1937). Their designation was accepted by some workers (e.g., Fitch, 1963; Dondale, 1969) but not by all (e.g., Kaston, 1948, 1972).

In a recent paper (Rovner, in press) I noted that the pattern of palpal insertions during mating in the species of Schizocosa studied so far is qualitatively distinct from that seen in $L y \cos a$ spp. Throughout most of the copulation in Schizocosa spp., one palp is inserted a number of times prior to each shift to the opposite palp. At the beginning of copulation the number of insertions in a series by each palp is relatively small. The number of insertions per series soon reaches a maximum and then, for the remainder of the copulation, gradually declines. In $L y \cos a$ spp., on the other hand, alternation of palps typifies the entire copulation. Re-insertions of the same palp are uncommon, constituting only a small percentage of the total number of insertions (Rovner, 1972).

Quantitative differences in copulatory behavior also may aid in characterizing these two genera. The duration of copulation and the total number of palpal insertions are much greater in Schizocosa saltatrix than in Lycosa spp. (Rovner, in press).

With these parameters in mind, I observed mating behavior in Schizocosa avida. The data obtained supported Gertsch and Wallace's (1937) reclassification of this species from Lycosa to Schizocosa.

\section{METHODS}

Penultimate individuals of $S$. avida were collected during early May, 1973, in a field near Amesville (Athens Co.), Ohio, USA.

${ }^{1}$ This study was supported in part by grant no. GB 35369 from the National Science Foundation.

Manuscript received by the editor July 23, 1973 
Molting to the adult instar occurred during early June, and observations were made during late June and early July. Spiders were housed separately and visually isolated from each other. They were fed mealworms (larvae of Tenebrio molitor) weekly and had a constant water supply.

Virgin spiders were paired in arenas for observation under fairly constant temperature $\left(23-25^{\circ} \mathrm{C}\right)$ and humidity $(60-65 \% \mathrm{RH})$ conditions. After observing one pair in a preliminary trial, I filmed portions of copulation in a second pair. The palpal insertion patterns of five other pairs were recorded for later analysis.

\section{RESUlts}

Copulatory behavior was similar in all seven pairs of $S$. avida observed. Throughout most of copulation, each palp was inserted repeatedly a number of times prior to a shift to the opposite palp. The length of such series showed the same pattern of variation in nearly all cases: few insertions per series at the beginning, increasing shortly thereafter to a maximum number of insertions per series, then a gradual decrease, eventually ending with a minimal number of palpal insertions. (In one male, insertions of the left palp began at the maximum series length; i.e., several "introductory" series of relatively short length were not shown by this male's left palp, although they did occur in the right palp.)

In the five recorded matings, each palp was inserted an average of I 58 times, for a mean total of 316 insertions per copulation. These copulations lasted $2.8 \pm \mathrm{r} .63(\mathrm{SD})$ hours. Other data are summarized in Table I.

Table I. Palpal insertions during copulation in five pairs of Schizocosa avida.

\begin{tabular}{|c|c|c|c|c|}
\hline \multirow[b]{2}{*}{ Pair no. } & \multirow{2}{*}{$\begin{array}{l}\text { Total no. } \\
\text { of series }\end{array}$} & \multirow{2}{*}{$\begin{array}{c}\text { Total no. } \\
\text { of insertions }\end{array}$} & \multicolumn{2}{|c|}{ Insertions per series } \\
\hline & & & Mean \pm SD & Range \\
\hline 1 & 21 & 241 & $11.5 \pm 14.7$ & $2-60$ \\
\hline 2 & 11 & 254 & $23.1 \pm 9.4$ & $4-35$ \\
\hline 3 & 31 & 213 & $6.9 \pm 5.0$ & $1-21$ \\
\hline 4 & 34 & 371 & $10.9 \pm 10.6$ & $1-48$ \\
\hline 5 & 37 & 501 & $13.5 \pm 10.4$ & $1-39$ \\
\hline Mean & 26.8 & 316.0 & $13.2 \pm 15.1$ & \\
\hline
\end{tabular}




\section{Discussion}

The copulatory pattern observed in Schizocosa avida was similar to that described in $S$. bilineata and S. crassipes (Montgomery, I903) and S. saltatrix (Rovner, in press). The occurrence of a series of insertions of one palp prior to a shift to the other palp differs from the rather strict alternation of palps seen in Lycosa chaperi (Bhatnagar and Sadana, I965), L. gulosa (Kaston, 1936), L. helluo (Kaston, I936; Nappi, 1965), L. punctulata (Rovner, unpublished data), and L. rabida (Montgomery, I903; Kaston, I936; Rovner, 1972). Furthermore, the pattern of variation in series length, which seems typical of Schizocosa spp. (Rovner, in press), was also present in S. avida. Thus, Gertsch and Wallace's (1937) placement of the former Lycosa avida into the genus Schizocosa on the basis of morphology has been strengthened by these behavioral data. The large number of palpal insertions (about 300) and the relatively long duration of copulation (about 2-3 hours) in $S$. avida also indicate a greater affinity to Schizocosa spp. than to Lycosa spp. (Rovner, in press).

Another aspect of behavior may be worth investigating in this regard. Knost and Rovner (in prep.) found that post-immobilization tying down of prey occurred in L. punctulata and L. rabida but not in $S$. crassipes. Whether this distinction is genus-specific or not must await studies of feeding behavior in other members of these two genera.

\section{Literature Cited}

Bhatnagar, R. D. S. and G. L. Sadana

1965. Sexual behaviour in Lycosa chaperi Simon (Arachnida: Araneida). J. Bombay Nat. Hist. Soc. 62: 568-573.

Chamberlin, R. V.

1904. Notes on generic characters in the Lycosidae. Canad. Ent. 36: 173-178.

1908. Revision of North American spiders of the family Lycosidae. Proc. Acad. Nat. Sci. Philad. 60: 158-318.

Dondale, C. D.

1969. Two new species of the spider genus Schizocosa (Araneida: Lycosidae) from the Great Lakes region. Canad. J. Zool. 47: 751-758.

FiTCH, H. S.

1963. Spiders of the University of Kansas Natural History Reservation and Rockefeller Experimental Tract. Misc. Publ. Mus. Nat. Hist. U. Kansas No. 33. 202 pp.

Gertsch, W. J. and H. K. Wallace

1937. New American Lycosidae with notes on other species. Amer. Mus. Nov. No. 919: 1-22. 
KASTON, B. J.

1936. The senses involved in the courtship of some vagabond spiders. Entomol. Amer., n. s. 16: 97-167.

1948. Spiders of Connecticut. Bull. State Geol. Nat. Hist. Surv. Hartford No. $70.874 \mathrm{pp}$.

1972. How to Know the Spiders. Wm. C. Brown Co., Dubuque, Iowa. $289 \mathrm{pp}$.

KNost, S. J. AND J. S. Rovner

In prep. Feeding behavior in wolf spiders (Araneae: Lycosidae): multiple-prey capture and tying-down.

MONTGOMerY, T. H., JR.

1903. Studies on the habits of spiders, particularly those of the mating period. Proc. Acad. Nat. Sci. Philad. 55 : 59-149.

NAPPI, A. J.

1965. Notes on the courtship and mating habits of the wolf spider Lycosa helluo Walckenaer. Amer. Midl. Nat 74: 368-373.

ROVNER, J. S.

1972. Copulation in the lycosid spider Lycosa rabida Walckenaer: a quantitative study. Anim. Behav. 20: 133-138.

In press. Copulation in the lycosid spider Schizocosa saltatrix (Hentz): an analysis of palpal insertion patterns. Anim. Behav. 

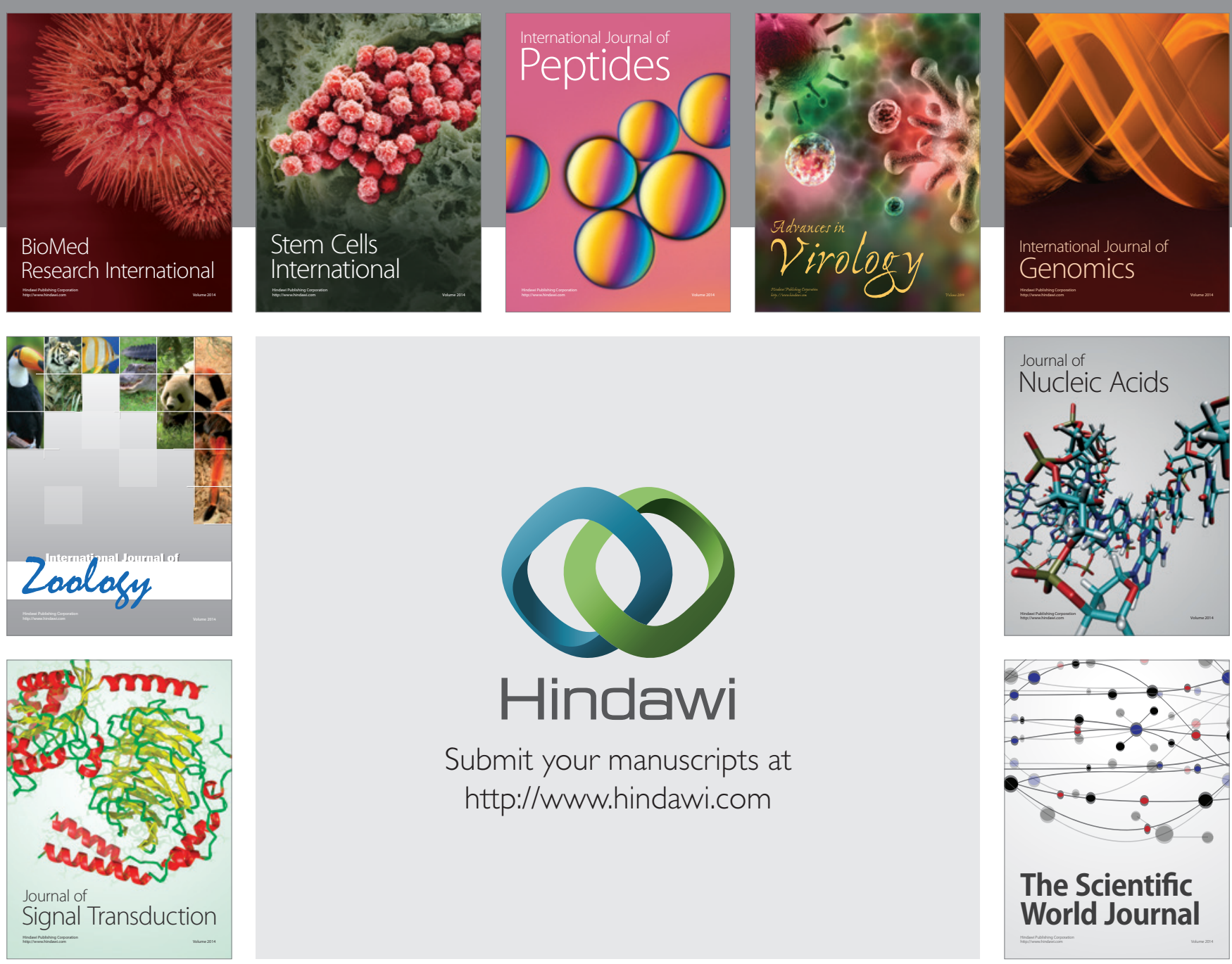

Submit your manuscripts at

http://www.hindawi.com
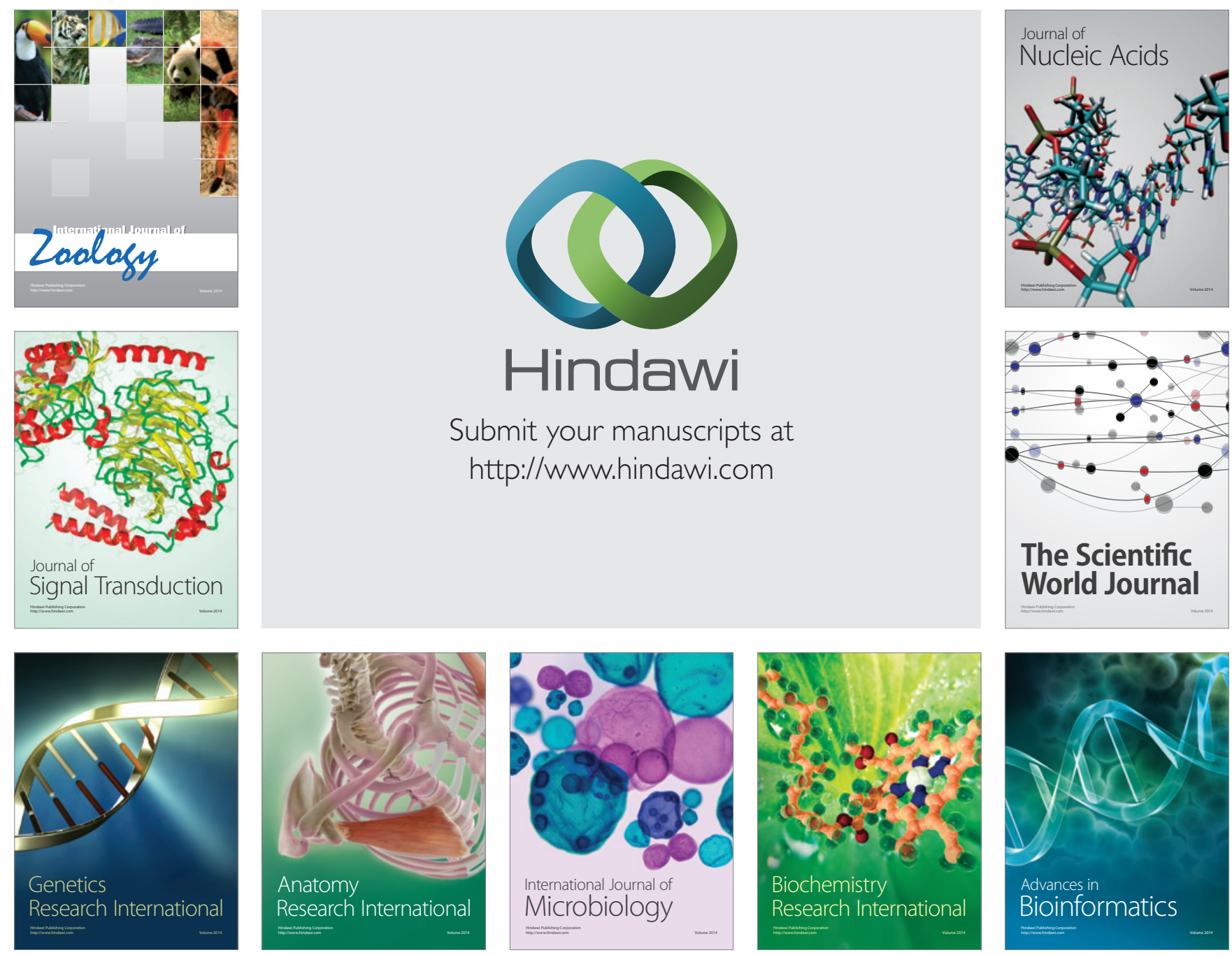

The Scientific World Journal
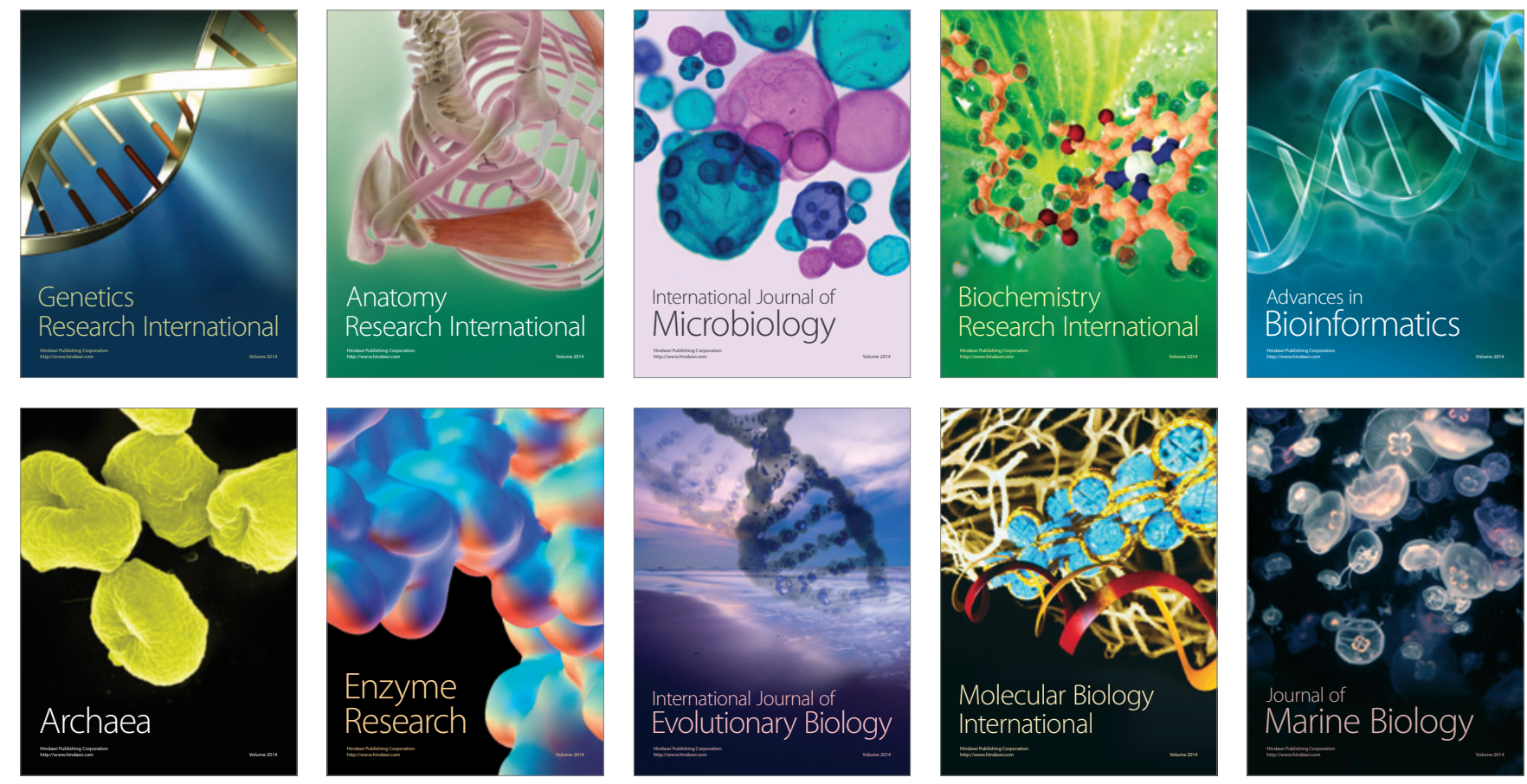